\title{
Research on Analysis and Innovation of University Teaching Archive Management
}

\author{
Mei Zhang \\ Archives \\ Linyi University \\ Linyi, China \\ Zhangmei7596@163.com
}

\author{
Peijiang Chen \\ School of Mechanical and Vehicle Engineering \\ Linyi University \\ Linyi, China \\ chenpeijiang@163.com
}

\begin{abstract}
The construction of teaching archives is one of the basic projects in colleges and universities, and it is related to the improvement of teaching management and teaching quality. The main contents of university teaching archives are briefly described, and their main features are analyzed. The importance and necessity of strengthening archive management in colleges and universities are discussed, especially the information construction. Focusing on serving users, this paper updates the ideas of teaching archive management, and puts forward the ideas of work innovation in strengthening team building, information engineering, and digital management and security.
\end{abstract}

Keywords-University teaching archives; Characteristic analysis; Idea renewal; Work innovation

\section{INTRODUCTION}

The teaching archives in colleges and universities refer to the historical records with preserving value directly or indirectly to students, schools and society in the teaching management activities. They are presented as the printed forms of paper or electronic document version. The core content of universities teaching archives includes student roll, class schedule, grades, examinations and other data generated from teaching activities, it is one of the important bases for the implementation of teaching management and teaching quality assessment.

The teaching archives management in colleges and universities is a series of management activities such as collection, collation, filing, development and utilization of these teaching archives, so as to provide services to teachers, students and the society. In the traditional teaching archives management, the completion of these tasks needs to rely on academic staff manual processing. Due to the business volume, low work efficiency, it is very easy to make mistake in the process of teaching archives handling and delivery.

In recent years, with the development and application of computer technology, communication technology and Internet technology, the information society is going mature [1]. At the same time, with the continuous expansion of enrollment in colleges and universities, and the deepening of teaching reform, the electronic archives increase sharply. In the information era, a large amount of stored electronic archives information is

This study was supported by the Teaching Quality Engineering Projects of Linyi University in 2016 and 2017. required to be quickly retrieved and utilized, which makes the construction of teaching archives information become an important part of university archives work. The construction of teaching archives informatization improves the scientificity, accuracy and high efficiency of teaching archives management.

Therefore, the construction of teaching archives is one of the basic projects of higher education, and it is the key of development of university archives. However, at present, there are certain problems in the management of university teaching archives, such as non-standard management system, unreasonable team structure, and so on. This not only hinders the development of teaching archives management, but also does impede the improvement of the teaching management. Therefore, based on analyzing the characteristics and importance of university archives management, the implementation strategies of improving the teaching archives are studied.

\section{ANALYSIS OF UNIVERSITY TEACHING ARCHIVE MANAGEMENT CHARACTERISTICS}

\section{A. The contents of university teaching archives}

The university teaching archives involve a very wide range, generally it contains the following aspects.

(1) Management documents

The administrative department for education and the university can issue all kinds of documents, such as education reform, professional and curriculum settings, and other related provisions, notifications, instructions.

(2) Teaching documents

The Teaching-related documents include teaching plans, teaching programs, syllabus, teaching reform programs, teaching papers, attendance records, teaching and research activities, and so on.

(3) Admission documents

The student enrollment related materials include enrollment brochures, professional presentation, enrollment plan, new students roster, and so on.

(4) Student documents 
The management documents related to student status include student status card, student registration form, student status change, and so on.

(5) Reward and punishment

The documents for students reward and punishment include test scores and ranking, graduation thesis, contest awards, innovation and entrepreneurship program, published papers, and so on.

For universities, these information has basically been electronic, and most of them are in electronic format.

\section{B. Characteristics of university teaching archives}

Compared with other archives in colleges and universities, the teaching archives have their own characteristics.

\section{(1) Professional and complicated contents}

The teaching management and teaching activities are very complicated. The teaching archives recorded these activities practice are also very complicated and varied. They are the most numerous and most complex part of the university archives.

The teaching archives in colleges and universities include teaching documents, teaching regulations, rules, and also include the teaching records of secondary schools, in addition to a large number of student teaching files. A huge number and complex type are important feature for the university teaching archives.

These aspects of teaching materials faithfully record and reflect the teaching process in colleges and universities. Its teaching and teaching management activities are highly professional activities.

\section{(2) Various forms and different ways of filing}

In general, colleges and universities have different levels of school running, such as Linyi University have three teaching levels, including graduate, undergraduate and specialist. Different educational levels have their own educational orientation, teaching requirements, curriculum setting and objectives, which bring their own characteristics of management, different classroom teaching methods, different student enrollment and learning characteristics, then resulting in different teaching documents.

The original information of the teaching archives are also varied, for example, from the traditional paper-based record to the current electronic graphics record, from the traditional preparation textbooks to the present multimedia courseware. Various forms of teaching archives have different archiving methods. The school schedule, graduation materials are archived based on teaching year, but the teaching administrative documents are archived based on the natural years. Such a wide range of archiving different ways of teaching archives need to be introduced into the information management [2].

\section{(3) Systematic and periodic contents}

The contents of teaching archives is systematic. The teaching archives are produced in all aspects of teaching practice and teaching management activities, involving all levels of teaching practice and management. Each student must has a systematical and complete set of archives in the process from entrance to graduation.

The periodicity teaching archives manifest as semester, school year, educational system. Each phase together constitutes a complete cycle. The training process for each student is a teaching cycle.

\section{(4) Dispersion and concentration}

Due to the division of teaching activities and management activities, the teaching materials produced tend to be scattered among various teaching departments, which makes these departments save a certain amount of files. However, according to the regulations of the university archives, there are also the principle of centralized management. Then, it also determines the decentralized and centralized management of university teaching archives.

\section{IMPORTANCE OF UNIVERSITY TEACHING ARCHIVES CONSTRUCTION}

\section{A. Teaching archives are an important link that can effectively promote teaching reform}

Teaching archives in colleges and universities are an important manifestation. To do a good job of teaching archives management in colleges and universities plays an important role in showing the process of teaching and learning. The detailed records of university teaching can objectively and effectively reflect the teaching activities over the years and have an important reference value for showing the teaching history and teaching reform in colleges and universities.

Based on these teaching information, the teaching quality assessment can be carried out. For example, in order to carry out the educational reform, it is important to research on teaching quality, and the university teaching archives can record the detailed information in the teaching process. The feedback information of teaching quality of students for teachers can be used to analyze the shortcomings of the teaching methods, then the teaching team can discuss and find scientific and reasonable solutions to improve the teaching methods. In addition, teachers can learn advanced teaching methods by sharing the teaching information [3].

These teaching activities gradually formed in the daily provide important reference for the healthy development of universities and innovation of teaching and scientific research, leadership decision-making and other work, and the teaching archives management is a very important part in colleges and universities. 


\section{B. Informationization of teaching archives is an inevitable result of social development and an important part of digital campus}

In the 21 st century, the rapid development of electronic information technology brings human society into the Internet era. The popularization of computer and information technology in colleges and universities has set new requirements for the management of teaching archives, then using digital means to innovate the management of teaching archives work is imperative.

As the scientific research and teaching sites, the colleges and universities has quick knowledge updating and advanced technology. To construct the digital campus, the educational administration system has been introduced, which not only enhances the modernization of teaching management, but also produced a large number of electronic files. This puts forward higher requirements for teaching archives management in colleges and universities and promotes the process of information management of teaching archives [4].

The management of university teaching archives must rely on computer network technology to speed up the pace of construction of archives information. By establishing a digital archival information system, it can meet the demand of teaching reform and development in colleges and universities.

\section{Information management of university teaching archives can improve utilization efficiency}

According to statistics, in paper-based traditional teaching archives management system, the effective utilization of archives is less than $10 \%$, and the value of teaching archives is far from fully used. The implementation of information management can effectively overcome this shortcoming, which can help to improve the efficiency of using teaching archives. Information is easy to achieve sharing of teaching resources, and users can quickly and efficiently retrieve them. The informatization management of teaching archives can enhance the socialized service function, satisfy the different utilization requirements of all kinds of users and provide applications from different ways.

\section{Information management of university teaching archives can improve teaching quality}

Through comprehensive analysis of teaching archives, the advanced, unique and effective teaching experience and methods can be summed to improve their teaching quality. At the same time, the standard management of teaching archives can record all the teaching-related activities such as outline, plan, experiment activities, and so on, so that the teachers must submit and save them regularly in time. Objectively, this approach can promote teachers to standardize the teaching process, and constantly improve their own requirements.

At the same time, the university managers can understand the teaching status by using the teaching archives information, assess the teaching quality, formulate reasonable teacher management mechanism and promote the healthy development of teaching staff.

\section{INNOVATION OF TEACHING ARCHIVES IN COLLEGES AND UNIVERSITIES}

The construction of teaching archives informationization in colleges and universities is a question about the overall situation of the modernization of higher education. However, due to various kinds of reasons, specially in a few local colleges and universities, there are many problems in the management of teaching archives [5]. Since the teaching archives is served for teachers and students, the traditional ideas and work methods should be innovated to improve the management quality.

\section{A. Idea innovation of university teaching archives}

(1) Make teaching as the service center

Teaching archives management should put teachers at the center, actively listen to their opinions, and innovative management methods connect with the service needs of the teachers, as far as possible to expand the scope of clients. The teaching files and information can be gotten to summarize teaching experience, carry out teaching reform and assess teaching quality.

(2) Position the service function

The vitality of teaching archives lies in the development and utilization. To guide the decision-making, serving teaching is the leading direction of teaching archives. The teaching archives management should adapt to the needs of the development of higher education reform, actively broaden the service areas and develop and utilize the teaching information. They should study the retrieval tools of teaching information resources, so as to effectively improve the utilization of teaching archives.

\section{(3) Make service more technological}

The computer management of teaching archives should be used to effectively continuously improve service quality. Digitization and information are the development trend of teaching archives service. The core of digitization is the database construction. Only the application of database and information network technology can open up new service areas and further improve the utilization rate of the teaching information resources.

(4) Make the management personnel comprehensive

According to the teaching need in colleges and universities, it is an important task to develop teaching archives information resources to make full use of them in teaching management and teaching. The administrative staff should focus on the characteristics of teaching information services, enhance service awareness, improve service methods, and strive to improve service capabilities and level.

Therefore, correctly handling the relationship between teaching archives work and teaching work can make the teaching archives play a greater role and benefit [6]. 


\section{B. Work innovation of university teaching archives}

In order to achieve the innovation of teaching archives, it is need to innovate in the following aspects.

(1) Strengthen the selection and training of qualified personnel

It is necessary to provide reasonable faculty. The business quality factors should be considered, especially the knowledge structure, age structure and pioneering awareness of the staff members. It is need to strengthen the continued education of archivists, organize archivists to learn the professional knowledge and computer application technology. The treatment and status of archivists must be effectively improved, fully considering their working ability in career promotion and job evaluation.

(2) Strengthen the information process of archive work

Informationization of teaching archives is an inevitable trend of development, so the digitization of archives can be enhanced to achieve information by information collection and organization through the Internet. The existing teaching archives resources should be systematically registered and counted, and the old teaching archives should be formulated and digitized. At the same time, the database must be constructed to ensure the practicality of teaching archives digitization.

(3) Digital management of teaching archives

It is important to carefully study the characteristics of electronic files and storage methods. Electronic document types maybe text, images, graphics, video and audio, multimedia, programs and databases. The main types of storage media are CD-ROM, flash disk, hard disk, network storage and so on. The Storage of digital archives have less demand on sites, but have very high demand on the environmental humidity and magnetic conditions. The storage of archived electronic documents should use specialized protection technology and equipment, regular testing and copying to ensure the reliability of electronic information and reduce human damage [7].

\section{(4) Security of teaching archives}

The basic requirement of teaching archives information is to make safety precautions. In the storage of digital teaching archives information, it should be equipped with the corresponding auxiliary equipment [8]. In order to secure the electronic teaching archives, the password verification should be enhanced to ensure the storage and access. At the same time, double archiving system, paper-based archiving and electronic archiving, can be adopted to ensure the safety and authenticity of teaching archives. The physical isolation between the LAN and external network can be used to prevent external attacks.

\section{CONCLUSIONS}

In order to meet the needs of the continuous reform and development of higher education, the work of teaching archives should adapt to the era development, it is necessary to strengthen management and promote the construction of teaching archives information. The management methods and technologies of teaching archives in colleges and universities need to be continuously strengthened and transformed.

In this process, the existing problems should be fully understood, so as to propose optimization and improvement measures and to promote the application of the teaching information management mode. Only by scientific and efficient management of teaching archives can guarantee the integrity and effectiveness of teaching archives resources so as to better guarantee the improvement of teaching quality, provide better teaching services to teachers and students, and improve the professional quality of students.

\section{ACKNOWLEDGMENT}

This study was supported by the Teaching Quality Engineering Projects of Linyi University in 2016 and 2017.

\section{REFERENCES}

[1] M. Zhang, P. Chen, Research on the Informatization Construction of University Archives Management, Advances in Social Science, Education and Humanities Research, vol. 157, pp. 342-345, 2017.

[2] T. Guo. Consideration of Innovation Model of Teaching Archives Management of Colleges and Universities, Journal of Higher Education, no. 1, pp. 21-23, 2018.

[3] W. Hu. Colleges' Teaching Archives Management: Problems and Countermeasures, Journal of Anhui Agricultural University (Social Sciences Edition), vol. 26, no. 5, pp. 63-65, 2017.

[4] X. Xing. Probe into the Administration on Universities Teaching Archives from the Information Point View, Journal of Jiamusi Education Institute, no. 12, pp.168-169, 2012.

[5] R. Li, X Huang. The Issue of Teaching Archives Informatization Construction of Local Universities and Colleges and Countermeasures Study, Shanxi Science and Technology, vol. 30, no. 2, pp. 95-97, 2015.

[6] Y. Xiong. On the Informational Administration of Teaching File of Colleges and Universities, Journal of Hunan Institute of Humanities, Science and Technology, no. 4, pp.180-182, 2007.

[7] Y. Cai. On Information Construction of Colleges and Universities Teaching Files., Journal of Hunan Institute of Humanities, Science and Technology, no. 2, pp. 148-150, 2009.

[8] Y. Zhao, D. Jin. Innovation Path of Teaching Archival Work of Colleges and Universities Under the Background of Informatization, Lantai World, no. 15, pp. 45-47, 2017. 